\title{
Early Spiritualist Discussions About the Distortions of Mediumistic Communications
}

\author{
Carlos S. Alvarado
}

carlos@theazire.org

Submitted April 5, 2020; Accepted May 5, 2020; Published December 15, 2020

https://10.31275/20201817

Creative Commons License CC-BY-NC

... The generality of communications ... are given in such a mode that they are liable to be affected by the mind of the medium,

because they are given through their use, in some measure, of the medium's mental powers.

—John W. Edmonds (1858, p. 7)

In a previous article I argued that the contributions of spiritualists to ideas about mediumship include more than defenses of discarnate agency (Alvarado, 2003). Among other things, they have contributed to recognition of the existence of distortions and difficulties in spirit communications, a topic mentioned in a recent JSE Editorial by Stephen Braude (2020) in which he cited statements about the subject by C. D. Broad (1962) and William James (1909). Although this was not the main topic of Braude's comments, I would like to refer to some nineteenthcentury examples of the literature in question if only to recognize the pioneering role of various spiritualists in discussing the subject, what one writer referred to as "imperfect messages by the telegraph from heaven" (Spirit communications, 1858, p. 4).

One example includes the ideas of American Universalist minister Samuel B. Brittan. In an article entitled "Cerebral Influence on Revelation," Brittan (1852) wrote:

In all ages, revelations from the Spiritual World have been essentially modified by the physical and mental characteristics of the persons 
through whom they have been given to mankind. In the process of influx, the elements of two minds are blended, and the revelation is the result of their mingled action. Sometimes this infusion is labored and difficult, and the spiritual influence is only perceptible in a slight abnormal quickening of the human faculties. Again the thought is directly inspired, but is left to be invested by the mind of the medium, from which it takes not only its coloring and clothing, but its specific form. (Brittan, 1852, pp. 39-40)

In his view the influence from the spiritual dimension, including biblical prophetic revelations, "usually conjoins itself to, and becomes cooperative with, the predominant elements of the mind" (p. 40). These elements were the usual patterns of thought and expression of the mind of the receiving person.

Similarly, another minister, social reformer Adin Ballou (1852), wrote that in mediums of inferior intellect: "Their own prejudices, will, imagination, low ideas, perverse sentiments, and peculiar absurdities of interior conception, must bias and characterize the communications, which any spirit should attempt to make through them" (p. 67). Thus the meaning of communicating spirits would be conveyed incorrectly. "It would be like the message of a Frenchman to an Englishman, rendered through an ignorant Dutchman, who had only a smattering of French and English. The Englishman might be puzzled to make anything decent of it" (p. 67).

The famous clairvoyant and visionary Andrew Jackson Davis also had something to say on the topic. He believed that:

The mind which has been, through the formative influence of prevailing education and custom, moulded into a receptacle for the entertainment of any particular notion, theory, or creed extant, is almost certain to unconsciously alter, modify, and arrange all impressions, from whatever source received, invariably in accordance with the state and style of its own growth and individual culture. And furthermore, it may be accepted as a principle, fully demonstrated in the world's history, that the Divine cannot flow into Human structures-the celestial cannot blend, intimately, with the terrestrial, without the former (the Divine) participating to a degree more or less obvious, in the imperfections which are infinitely and eternally consequent upon, and inseparably connected with, a physical or material state of existence. Discord 
and contradiction, therefore, growing out of the intimate association or conjunction of the spiritual with the material, must invariably and everywhere be more or less apparent. This fact will certainly appear, notwithstanding the honesty or good intentions of the media, ${ }^{1}$ or that entire passivity of mind which Truth requires. (Davis, 1853, p. 203)

Another example comes from the writings of a prominent spiritualist and student of mediumistic phenomena, American Judge John W. Edmonds. He wrote as follows in the second volume of Spiritualism, an early classic on the subject authored by Edmonds and physician George T. Dexter (1855), who wrote on the subject as students of the topic, but also in terms of their experiences as mediums. The following is from the volume's Introduction by Edmonds:

The visions which I have are . . . impressed on my mind as vividly and distinctly as any material object possibly can be, yet in giving them to others, I must rely upon and use my own powers of observation, my own memory, my own command of language, and I not unfrequently labor under the difficulty of feeling that there is no word known to me that is adequate to conveying the novel idea communicated. I am often conscious that I fail, from poverty of language, in conveying the sentiment I receive with the same vigor and clearness with which it comes to me. So it is also with what I may call the didactic teachings through me. Sometimes the influence is so strong, that I am given, not merely the ideas, but the very words in which they are clothed, and I am unconscious of what I am going to say until I actually say it. At other times the thought is given me sentence by sentence, and I know not what idea or sentence is to follow, but the language used is my own and is selected by myself from my own memory's storehouse. And at other times the whole current of thought or process of reasoning is given me in advance, and I choose for myself the language and the illustrations used to convey it, and sometimes the order of giving it. But in all these modes there is more or less of myself in them, more or less of my individuality underlying it all ...

I have noticed the same thing in the Doctor [Dexter], and more than all that, I have observed in both of us that our communications not only at times contain what may be called Americanisms, but expressions peculiar to our respective professions.

It is, therefore, rarely that either of us can say that the 
communications through us are precisely what the spirits designed they should be, and as they designed them; and consequently it will never do to receive them as absolute authority, however agreeable they may be or however consonant to other teachings...

Sometimes it is more apparent than at others, owing to many causes ever at work around us; sometimes it is owing to the physical condition of the medium, and sometimes to his mental state; sometimes to the atmosphere; sometimes to locality—some localities, such as high and hilly places being more favorable than such as are low and swampy; sometimes to the condition of those who are present, whether in a state of harmony or discord, and very frequently to the state and condition of the spirits who are professing to commune, and their aptitude to the task...

There is another cause, and that is, the passiveness or otherwise of the mediums to the influence at work with them. Sometimes they resist with a very determined will, and it is impossible for others, and often even for ourselves, to know when the operation of that will is entirely overcome, or how much of its influence may hang around and stain the communication with its taint of mortal life. Sometimes timidity and diffidence will color and sometimes vanity and fanaticism distort the teaching of the spirits. Often the want of confidence will warp them; for, strange as it may appear! there are mediums who are not Spiritualists, and who, unaccustomed to the examination of their own minds, can not discriminate between their operation and the spirit-influence; and as often an overweening credulity will put awry that which was designed to be plain and straightforward. (Edmonds \& Dexter, 1855, pp. 39-41)

Another example was American attorney and inventor Joel Tiffany. He wrote in his book Spiritualism Explained that the significance of communications depended on the medium's translation of messages:

Suppose the Spirits make a communication, they make it in words. These words only address your consciousness through your understanding, and you make them mean according to your understanding of them. If the Spirit makes a communication by pantomime, it still appeals to your understanding, and depends upon your translation to give it significance. There may be error in the communication and in yourself, so that the error will be double. (Tiffany, 1856, p. 110) 
My final example is from France, from the pen of Allan Kardec (pseudonym of educator Hippolyte-Léon Denizard Rivail). He wrote that when a spirit communicates in a language known to the medium he uses the words he finds there to convey his thoughts. If the communicator uses a language different from the medium's the latter's mind would not have the necessary words, and letter-by-letter dictation would be required. "If the medium can neither read nor write, she does not even possess the letters; you must therefore lead her hand like a schoolgirl; and this is an even greater material difficulty to overcome" (Kardec, 1862, p. 281, my translation).

Many other examples could be cited (e.g., Crowell, 1879, Chapter 10; Inaccuracies in communications from the spirit life, 1857; Spicer, 1853, p. 150; Wolfe, 1874, p. 96), including many published later in the Twentieth Century (e.g., Carrington, 1937, Part 1, Chapter 7; Firebrace, Vigurs, \& Leaf, 1954; Leaf, 1911). ${ }^{2}$ Most of these writings focused on confusions between presumably veridical messages and the content of the medium's mind, including such things as imagery and recollections. But this literature did not include suggestions for research, nor actual studies of the problem. I have presented some ideas about possibilities for research on the subject in a discussion of mediumistic mentation published in this journal (Alvarado, 2010).

In the meantime, my main point is a strictly historical one. That is, we need to recognize the conceptual contribution of spiritualists to psychical research, which extends beyond generating interest in mediumship and providing a context for its development and practice. This contribution includes the development of various other theoretical ideas that, regardless of their validity, were influential in the study of mediumship and its conceptualizations. ${ }^{3}$

\section{NOTES}

1 Mediums were sometimes called "media" in the early spiritualistic literature (e.g., Ballou, 1852, p. 61; Capron, 1855, p. 392; Hare, 1855, p. 159).

2 The psychical research literature also has interesting discussions, as seen in studies about medium Leonora E. Piper (Hodgson, 1898; Sidgwick, 1915). Also important were James $\mathrm{H}$. Hyslop's numerous 
writings about the "pictographic" process (e.g., Hyslop, 1914, 1919, Chapter 10; see also Alvarado, 2009). This was a process in which "the communicator manages to elicit in the living subject a sensory phantasm of his thoughts, representing, but not necessarily directly corresponding to, the reality" (Hyslop, 1919, p. 111). The sensory impression could be in various modalities, depending on the medium. Hyslop argued that messages could be distorted when the content of the medium's subconscious mind interfered with the interpretation of the imagery involved, or when stray or peripheral imagery came from the communicator.

3 This includes communications from the living, and ESP from the living explanations of mediumship (Alvarado, 2003), as well as ideas of psychic forces, particularly in relation to physical mediumship (Alvarado, 2006).

\section{REFERENCES}

Alvarado, C. S. (2003). The concept of survival of bodily death and the development of parapsychology. Journal of the Society for Psychical Research, 67(2), 65-95.

Alvarado, C. S. (2006). Human radiations: Concepts of force in mesmerism, Spiritualism and psychical research. Journal of the Society for Psychical Research, 70(3), 138-162.

Alvarado, C. S. (2009). James H. Hyslop and the pictographic process in mediumistic communications. Paranormal Review, 49, 3-7.

Alvarado, C. S. (2010). Investigating mental mediumship: Research suggestions from the historical literature. Journal of Scientific Exploration, 24(2), 197-224.

Ballou, A. (1852). An exposition of views respecting the principal facts, causes, and peculiarities involved in spirit manifestations. Bela Marsh.

Braude, S. E. (2020). Cosmic aesthetics [Editorial]. Journal of Scientific Exploration, 34(1), 5-12. DOI: 10.31275/2020/1755

Brittan, S. B. (1852). Cerebral influence on revelation. The Shekinah, 2, 39-43.

Broad, C. D. (1962). Lectures on psychical research. Routledge \& Kegan Paul.

Capron, E. W. (1855). Modern Spiritualism, its facts and fanaticisms, its consistencies and contradictions. Bela Marsh.

Carrington, H. (1937). The psychic world. G. P. Putnam's Sons.

Crowell, E. (1879). The spirit world: Its inhabitants, nature, and philosophy. Colby \& Rich.

Davis, A. J. (1853). The present age and inner life: A sequel to spiritual intercourse: Modern mysteries classified and explained. Partridge and Brittan.

Edmonds, Judge [J. W.] (1858). Uncertainty of spiritual intercourse (Spiritual Tracts No. 4). [No publisher] 
Edmonds, J. W., \& Dexter, G. T. (1855). Spiritualism (Vol. 2). Partridge \& Brittan.

Firebrace, R. C., Vigurs, H. L., \& Leaf, H. (1954). Spirit communication and the mind of the medium, the sitter, the communicator. Almorris Press.

Hare, R. (1855). Experimental investigation of the spirit manifestations. Partridge \& Brittan.

Hodgson, R. (1898). A further record of observations of certain phenomena of trance. Proceedings of the Society for Psychical Research, 13(part 33), 284-582.

Hyslop, J. H. (1914). A hypothetical process of communication. Journal of the American Society for Psychical Research, 8(8), 377-389.

Hyslop, J. H. (1919). Contact with the other world. Century.

Inaccuracies in communications from the spirit life. (1857, September 10). Banner of Light, 5-6.

James, W. (1909). Report on Mrs. Piper's Hodgson-control. Proceedings of the Society for Psychical Research, 23(part 58), 2-121.

Kardec, A. (1862). Spiritualisme expérimental: Le livre des médiums (2nd ed.). Didier.

Leaf, H. (1911). Difficulties of spirit communication. Light, 31(1606), 496-497.

Sidgwick, Mrs H. [E. M.]. (1915). A contribution to the study of the psychology of Mrs. Piper's trance phenomena. Proceedings of the Society for Psychical Research, 28(part 71), 1-657.

Spicer, H. (1853). Sights and sounds: The mystery of the day: Comprising an entire history of the American "spirit" manifestations. Thomas Bosworth.

Spirit communications. (1858, January 9). Banner of Light, 4.

Tiffany, J. (1856). Spiritualism explained. Graham and Ellinwood.

Wolfe, N. B. (1874). Startling facts in modern Spiritualism. No publisher. 